\title{
MUTATION STATUS AND IMMUNOHISTOCHEMICAL CORRELATION OF EGFR MUTATIONS IN GASTROINTESTINAL STROMAL TUMORS
}

\author{
Ozkayalar $\mathrm{H}^{1}$, Ergoren $\mathrm{MC}^{2,3, *}$, Tuncel $\mathrm{G}^{2,3}$, Kurt $\mathrm{S}^{4}$, Cevik E ${ }^{4}$, Ozemri Sag S
} Yilmaz Ozguven B ${ }^{5}$, Kabukcuoglu $F^{5}$, Mocan $\mathrm{G}^{1,2}$, Temel ŞG $\mathrm{G}^{4,6,7, *}$

"Corresponding Authors: Associate Professor Mahmut C. Ergoren, Department of Medical Genetics, Faculty of Medicine, Near East University, Near East Boulevard, 99138 Nicosia, Northern Cyprus. Tel.: +90-392-444-0535. Fax: +90-392-223-6461. E-mail: mahmucerkez.ergoren@neu.edu.tr. And/or: Associate Professor Sehime G. Temel, Department of Medical Genetics, Faculty of Medicine, Bursa Uludag University, Özlüce Görüjke Kampüsü, 16059 Nilüfer, Bursa, Turkey. Tel.: +90-224-295-0000. Fax:+90-224-295-0019. E-mail: sehime@uludag.edu.tr.

\begin{abstract}
Being one of the leading causes of cancer deaths worldwide and their resistance to conventional treatment methods, made gastrointestinal stromal tumors (GISTs) one of the hot topics in medical research areas in the past decade. To investigate molecular alterations underlying the tumor is of great importance to be able to develop new, targeted treatment options. In this study, GIST samples obtained from 40 Turkish patients were analyzed for actionable epidermal growth factor receptor $(E G F R)$ mutations that are related to treatment regimes in non small cell lung cancer (NSCLC) to understand whether EGFR expression is altered in GISTs. Established alterations in EGFR can make the use of tyrosine kinase inhibitors possible, which are currently used in cancer therapy, especially in NSCLC. Our results indicated that EGFR mutations are rare in GISTs. Further research is needed to sequence
\end{abstract}

\footnotetext{
${ }^{1}$ Department of Pathology, Faculty of Medicine, Near East University, Northern Nicosia, Cyprus

${ }^{2}$ Department of Medical Biology, Faculty of Medicine, Near East University, Northern Nicosia, Cyprus

${ }^{3}$ Research Center of Experimental Health Sciences (DESAM), Faculty of Medicine, Near East University, Northern Nicosia, Cyprus

${ }^{4}$ Department of Medical Genetics, Faculty of Medicine, Bursa Uludag University, Bursa, Turkey

${ }^{5}$ Department of Pathology, Sisli Hamidiye Etfal Education and Research Hospital, University of Health Sciences, İstanbul, Turkey

${ }^{6}$ Department of Embryology and Histology, Faculty of Medicine, Bursa Uludag University, Bursa, Turkey

${ }^{7}$ Department of Translational Medicine, Bursa Uludag University, Health Sciences Institute, Bursa, Turkey
}

whole coding regions of the gene to investigate new actionable mutations in EGFR in an increased sample size.

Keywords: Epidermal growth factor receptor $(E G F R)$ gene; Gastrointestinal stromal tumors (GISTs); Targeted therapy.

\section{INTRODUCTION}

Gastrointestinal stromal tumors (GISTs) are the most common mesenchymal tumors of the gastrointestinal (GI) tract, generally occurring after the age of 50. A majority of all GISTs occur in the stomach ( $\sim 60.0 \%)$, followed by the jejenum/ileum, duodenum, rectum, appendix, colon and rarely, in the oesophagus [1]. Aggressive GISTs can me-tastasize to the liver and throughout the abdomen [2]. Patients frequently develop abdominal pain, nausea, fatigue and GI bleeding as the symptoms of GIST, while some remain asymptomatic [3]. Gastrointestinal stromal tumors are one of the leading causes of cancer deaths worldwide, therefore, understanding its molecular background and developing targeted therapy techniques are of high importance [4,5].

At the cellular level, GISTs are known to have a broad morphological spectrum. In general, they are divided into three histological subtypes: the spindle cell type being the most common, epithelioid type and rarely mixed spindle cell and epithelioid type [6]. In the last decade, investigation of alterations at the molecular level underlying the disease, greatly revolutionized both diagnosis and treatment strategies. The vast majority of GISTs were found to have activating mutations in the KIT receptor tyrosine kinase, which is accepted as a GIST biomarker by the European Group on Tumor Markers (EGTM). Currently, detection of CD117 (c-KIT) by immunohistochemistry is the method used for 
diagnosis or confirmation of imaging-based diagnoses [7]. Less frequently, mutations in the gene platelet-derived growth factor receptor $\alpha$ (PDGFRA) are detected in the KIT-negative GISTs [8-11]. On the other hand, expression or function of another well-known receptor tyrosine kinase, the epidermal growth factor receptor $(E G F R)$ gene was found to be frequently altered in colorectal and gastric cancers as in many other tumor types $[12,13]$. The $E G F R$ family comprises ERBB2/HER2, ERBB3/HER3 and ERBB4/HER4 as well as the $E G F R$ itself [14]. Binding of a ligand causes dimerization of receptors that leads to autophosphorylation of tyrosine residues, which then phosphorylates downstream signaling molecules triggering cellular pathways involved in DNA synthesis, cell growth, proliferation and differentiation [15].

Before the investigation of such molecular alterations and development of targeted treatments, complete surgical resection was the only potentially curative treatment of choice for localized GISTs [3]. However, use of tyrosine kinase inhibitors (TKIs) and monoclonal antibodies (mAbs) as targeted therapy agents to inhibit carcinogenic actions of the tyrosine kinases in various human cancers, was shown to prolong overall survival and progression-free survival in cancers including GISTs, breast cancer, nonsmall cell lung cancer (NSCLC), and pancreatic cancers in the last decade [16].

Therefore, the importance of being able to detect mutations in cancer patients causing the disease and prescribing a therapy accordingly is clear. To the best of our knowledge, even though it is studied extensively in many tumor types, frequency of somatic EGFR mutations in GISTs has not been studied in the Turkish population before. In this study, mutation status of the EGFR gene and immu-nohistochemical marker changes in GISTs from 40 different Turkish patients was investigated to compare and correlate the mutation status with histopathological changes in the patient samples.

\section{MATERIALS AND METHODS}

Study Design, Participants and Immunohistochemical Analysis. In this study, 40 patients' samples (19 females, 21 males) who were diagnosed with GIST, were found to be positive with c-KIT immunohistochemistry staining (Clone YR145; Cell Marque Corporation, Rocklin, CA, USA) and DOG-1 (Clone K9; Leica Biosystems, Wetzlar, Germany) between January 2013 and June 2018, at the Pathology Department of Şişli Hamidiye Etfal Education and Research Hospital, Istanbul, Turkey.

All 40 tumor samples were fixed in $10.0 \%$ formalin for 10 hours at room temperature. Then they were embedded in paraffin sections ( $4 \mu \mathrm{m}$ thick) and mounted onto positively-charged glass slides. Immunostaining was performed with an automated immunostainer (Ventana Medical Systems, Inc., Tucson, AZ, USA) using the EGFR antibody (Clone: EGFR.113, dilution: 1/200, Novocastra Laboratories Ltd., Newcastle, Tyne and Wear, UK) at the Pathology Department of Near East University Hospital, Nicosia, Cyprus. The stained slides were evaluated semiquantitatively by two independent pathologists. The EGFR scoring system was referred from the study of Edris et al. [17] as 0: absence of any staining; 1 : weak staining (diffuse or focal); 2 : strong staining (diffuse or focal).

Genetic Analysis. DNA was isolated from the tumor tissue embedded in paraffin blocks using QIAamp ${ }^{\circledR}$ DNA FFPE Tissue Kit (Cat.: 56404, Qiagen GmbH, Hilden, Germany) according to the manufacturer's protocol. Then, Therascreen ${ }^{\circledR}$ EGFR Pyro Kit (Cat.: 971480, Qiagen $\mathrm{GmbH}$ ) was used for sequence-based detection and quantitation of mutations in the exons 18 (codon 719), exon 19 (deletion), exon 20 (codons 768 and 790) and exon 21 (codons 858 and 861) of the EGFR gene, according to the manufacturer's protocol, using $10 \mathrm{ng}$ of genomic DNA extracted from the tumor tissue at the Department of Medical Genetics, Faculty of Medicine, Bursa Uludag University, Bursa, Turkey.

\section{RESULTS}

Nineteen female and 21 male patients (total 40) participated in the study with average ages 57.3 and 62.4, respectively. Minimum and maximum ages in women were 24 and 78, whereas it was 45 and 77 in men. Age and gender of the patients, location and cell types of tumors are shown in Table 1 below.

At the end of the molecular genetic analysis, no mutations were detected in the most common six hot-spot regions that included codon 719 in exon 18, deletion of exon 19, codons 768 and 790 in exon 20 and codons 858 and 861 in exon 21 of the EGFR gene tested in 40 different somatic GIST patients. Probably, immunohistochemical analyses showed no expression of EGFR in the tested somatic tumor samples (Figure 1).

\section{DISCUSSION}

Gastrointestinal stromal tumors gained particular interest over the last decade as they are the most common mes-enchymal neoplasm in the GI tract, accounting for $\sim 1.0 \%$ of all GI tumors, and are resistant to conventional chemotherapy and radiotherapy options $[6,18]$. In the era of precision medicine, discovery of particular molecular aberrations in GISTs promised novel treatment options applicable to the patients. Most GISTs were found to have 
BALKAN JOURNAL OF MEDICAL GENETICS

Ozkayalar H, Cerkez Ergoren M, Tuncel G, Kurt S, Cevik E, Ozemri Sag S, Yilmaz Ozguven B, Kabukcuoglu F, Mocan G, Temel ŞG

Table 1. Patient details such as age, gender, tumor locations, cell types and EGFR gene mutation status are shown.

\begin{tabular}{|c|c|c|c|c|c|c|c|c|}
\hline \multirow[t]{2}{*}{ Sex } & \multirow[t]{2}{*}{$\begin{array}{c}\text { Mean } \\
\text { Age }\end{array}$} & \multirow[t]{2}{*}{$\begin{array}{c}\text { Tumor } \\
\text { Location (\%) }\end{array}$} & \multirow[t]{2}{*}{$\begin{array}{c}\text { Tumor Cell } \\
\text { Type (\%) }\end{array}$} & \multicolumn{4}{|c|}{$\begin{array}{c}\text { Status of Analyzed } E G F R \text { Gene Mutations } \\
\text { Exons (codons) }\end{array}$} & \multirow[t]{2}{*}{$\begin{array}{c}E G F R \\
\text { Expression }\end{array}$} \\
\hline & & & & $\begin{array}{c}18 \\
(719)\end{array}$ & $\begin{array}{c}19 \\
\text { (deletion) }\end{array}$ & $\begin{array}{c}20 \\
(768 ; 790)\end{array}$ & $\begin{array}{c}21 \\
(858 ; 861)\end{array}$ & \\
\hline \multirow[t]{5}{*}{$\mathrm{F}$} & $57.2 \pm 5.6$ & duodenum (21.5) & spindle cell (100.0) & wild type & wild type & wild type & wild type & negative \\
\hline & & ileum (10.5) & epithelioid (100.0) & wild type & wild type & wild type & wild type & negative \\
\hline & & small intestine (26.3); & $\begin{array}{l}\text { epithelioid (20.0); } \\
\text { mixed (60.0); } \\
\text { spindle cell (20.0) }\end{array}$ & wild type & wild type & wild type & wild type & negative \\
\hline & & stomach (38.8) & $\begin{array}{l}\text { spindle cell (57.0); } \\
\text { mixed (14.2); } \\
\text { epithelioid (28.8) }\end{array}$ & wild type & wild type & wild type & wild type & negative \\
\hline & & transverse colon (5.2) & mixed (100.0) & wild type & wild type & wild type & wild type & negative \\
\hline \multirow[t]{7}{*}{$\mathrm{M}$} & $62.6 \pm 10.5$ & colon $(9.5)$ & spindle cell (100.0) & wild type & wild type & wild type & wild type & negative \\
\hline & & descending colon (4.7) & mixed (100.0) & wild type & wild type & wild type & wild type & negative \\
\hline & & duodenum (4.7) & spindle cell (100.0) & wild type & wild type & wild type & wild type & negative \\
\hline & & ileum (4.7) & mixed (100.0) & wild type & wild type & wild type & wild type & negative \\
\hline & & jejenum (4.7) & spindle cell (100.0) & wild type & wild type & wild type & wild type & negative \\
\hline & & small intestine (19.0) & $\begin{array}{l}\text { spindle cell }(25.0) \\
\text { mixed }(75.0)\end{array}$ & wild type & wild type & wild type & wild type & negative \\
\hline & & Stomach (52.4) & $\begin{array}{l}\text { spindle cell (54.5); } \\
\text { mixed (36.3); } \\
\text { epithelioid (9.2) }\end{array}$ & wild type & wild type & wild type & wild type & negative \\
\hline
\end{tabular}

EGFR: epidermal growth factor receptor; F: females; M: males.
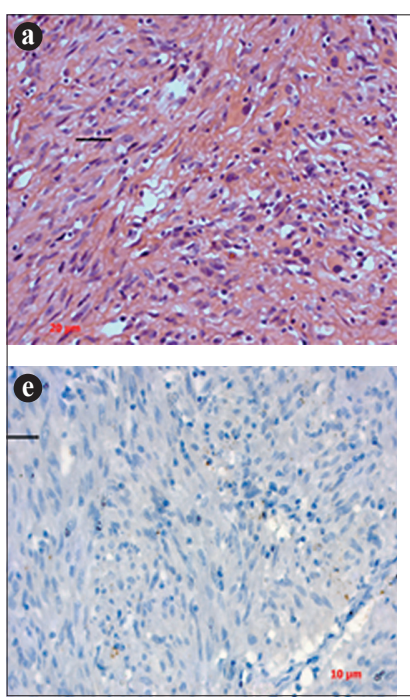
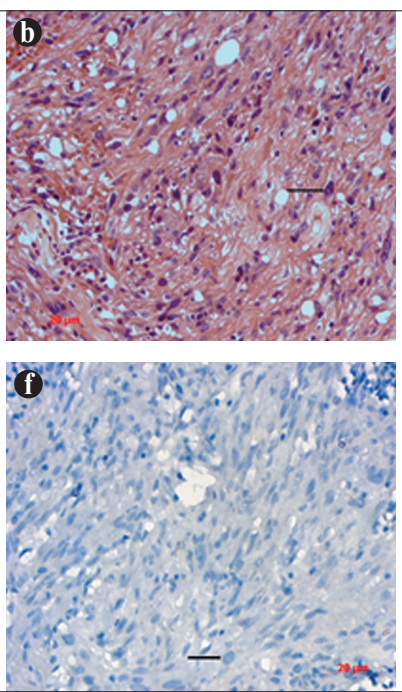
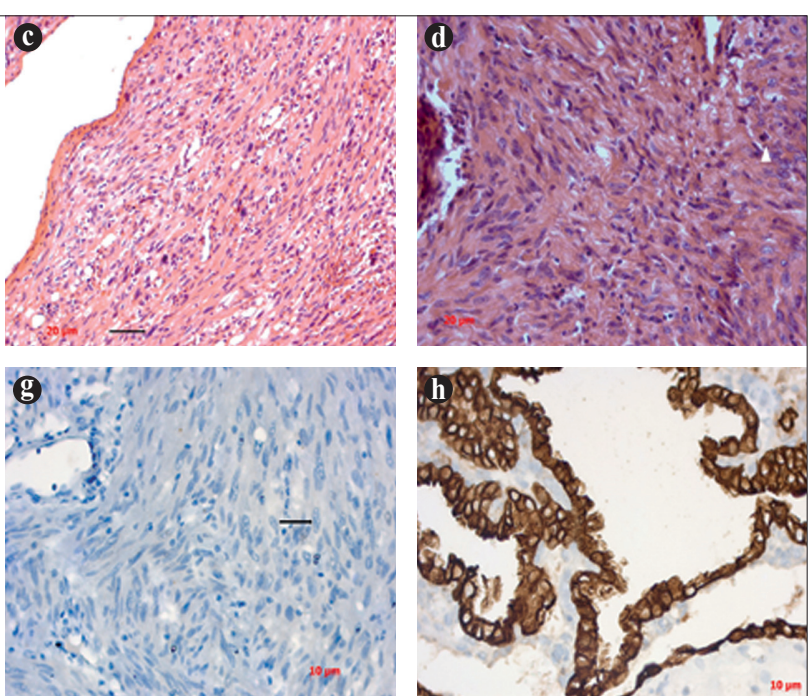

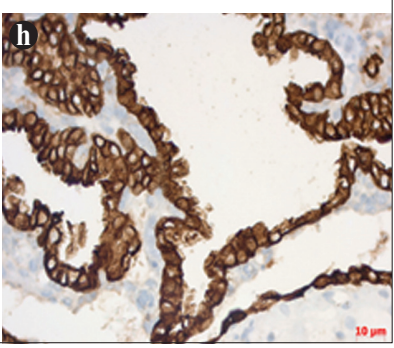

Figure 1. Images a-d show immunohistochemical staining of GIST samples with spindle-shaped tumor cells, negative for $E G F R$ expression. Images e-f indicate hematoxylin and eosin staining of GIST samples with spindle-shaped tumor cells. Image $\mathbf{g}$ represents the positive control, expressing EGFR. All images were taken in $40 \times$ magnification. Image $\mathbf{h}$ represents the control EGFR sample from a chorionic villus sample.

activating mutations in two closely related tyrosine kinase receptors, KIT and PDGFRA. When they are mutated, the receptors become constitutively active and trigger uncontrolled cell proliferation leading to tumor formation. Therefore, use of specific tyrosine kinase inhibitors such as imatinib mesylate, restores normal signaling and was proved useful in the treatment of GISTs [18]. Discovery of such molecular markers and targeted treatments help to reduce the time consumed for diagnosis and decision of treatment method, improving survival times of patients. 
In this context, different alterations in the EGFR gene have also been used as a molecular marker for various tumor types, allowing the use of kinase inhibitors as effective treatment strategies in patients. The EGFR gene can gain oncogenic activity through structural rearrangements, gene amplifications and activating point mutations [19]. Point mutations generally cluster in the region that codes for the tyrosine kinase domain (exons 18-21) of the receptor, which results in constitutive activation of the encoded EGFR even in the absence of its ligand, resulting in excessive cell growth and proliferation leading to tumorigenesis [12].

In colorectal cancers, the EGFR gene copy number was shown to be high compared to normal tissue, somatic mutations affecting the kinase domain of the protein was seen frequently in NSCLC [20]. In gastric cancers, overexpression of the gene was well described, however, clinical trials targeting EGFR mostly returned disappointing results, probably because the patient selection procedure was not biomarker-assisted [12,21]. Additionally, aberrations in $E G F R$ are frequent in other tumors including breast, brain and ovary. Use of anti-EGFR monoclonal antibodies or EGFR-targeted tyrosine kinase inhibitors is proven to be successful in these tumors. In addition to its specificity, TKIs in general are administrated orally and provide a rapid tumor response, unlike conventional cytotoxic chemotherapy options [22].

In this study, EGFR status of 40 somatic GIST samples derived from stromal mesenchymal origins were analyzed to understand whether any EGFR aberrations are present in GISTs to be potentially used in diagnosis and treatment of these tumors. Despite previous studies [20,22,23] that showed no significant association between EGFR expression and prognostic analysis of GISTs, a study by Shi et al. [24] indicated that only a small percentage of GISTs carry somatic EGFR mutations but speculated that it may play a role in the development and progression of the GISTs. However, the literature about the EGFR status in GISTs is still very limited. In the present study. The GIST samples were tested for therapy-targeted somatic EGFR mutations that are found in many cancer types (such as lung, breast, etc.) in the kinase domain region by targeted sequencing, and immunohistochemistry was also used for detection of any overexpression of the EGFR at the protein level. Data analyses indicated no mutations and no overexpression in the samples tested. The results explain that EGFR mutations potentially left out from primarily GISTs tumors. Therefore, these EGFR mutation-free GISTs have likely been resistant to TKI therapies. On the other hand, Apicella et al. [25] indicated that EGFR cannot be totally ignored as a potential target in gastric cancer, the EGFR pathway function should be examined for each subject considering the inhibition of the EGFR. According to another study [26], a phosphorylation of the EGFR pY1068 type was observed in the chromosomal instability as well as EGFR mutations, which vascular endothelial growth factor receptor 2 (VEGFR) targeted antibodies were recommended to gastric cancer patients.

The main limitation of our study was the sample size. The study requires more patient samples and clinical data to support somatic EGFR mutations as serving as a prognostic biomarker for clinical decision making in GISTs. Moreover, we have only examined known driver mutations, which respond to treatment in other cancer types such as lung cancer. In the future study, full coding gene region sequencing analysis of the EGFR gene can be designed.

Overall, supporting the previous study by Shi et al. [24], our results indicate that somatic EGFR mutations are rare in GISTs. Despite a bigger sample size being needed to confirm this conclusion [27], these primary data support that EGFR-tyrosine kinase inhibitor (TKI) treatment alone may not have impact on patients' survival. However, it should be further investigated whether EGFR has a role in the initiation of these tumors.

Declaration of Interest. The authors report no conflicts of interest. The authors alone are responsible for the content and writing of this article.

\section{REFERENCES}

1. Miettinen M, Lasota J. Gastrointestinal stromal tumors: Pathology and prognosis at different sites. Semin Diagn Pathol. 2006; 23(2): 70-83.

2. DeMatteo RP, Lewis JJ, Leung D, Mudan SS, Woodruff JM, Brennan MF. Two hundred gastrointestinal stromal tumors: Recurrence patterns and prognostic factors for survival. Ann Surg. 2000; 231(1): 51-58.

3. Lv M, Wu C, Zheng Y, Zhao N. Incidence and survival analysis of gastrointestinal stromal tumors in Shanghai: A population-based study from 2001 to 2010. Gastroenterol Res Pract. 2014; 2014: 83416

4. Pisani P, Parkin DM, Bray F, Ferlay J. Estimates of the worldwide mortality from 25 cancers in 1990. Int J Cancer. 1999; 83(1): 18-29.

5. Ferlay J, Soerjomataram I, Dikshit R, Eser S, Mathers $\mathrm{C}$, Rebelo $\mathrm{M}$, et al. Cancer incidence and mortality worldwide: sources, methods and major patterns in GLOBOCAN 2012. Int J Cancer. 2015; 136(5): E359-E386.

6. Zhao X, Yue C. Gastrointestinal stromal tumor. J Gastrointest Oncol. 2012; 3(3): 189-208. 
7. ESMO/European Sarcoma Network Working Group. Gastrointestinal stromal tumors: ESMO Clinical Practice Guidelines for diagnosis, treatment and follow-up. Ann Oncol. 2012; 23(Suppl 7): vii49-vii55.

8. Lux ML, Rubin BP, Biase TL, Chen CJ, Maclure T, Demerti $\mathrm{G}$, et al. KIT extracellular and kinase domain mutations in gastrointestinal stromal tumors. Am J Pathol. 2000; 156(3): 791-795.

9. Heinrich MC, Corless CL, Demetri GD, Blanke CD, von Mehren $\mathrm{M}$, Joensuu $\mathrm{H}$, et al. Kinase mutations and imatinib response in patients with metastatic gastrointestinal stromal tumor. J Clin Oncol. 2003; 21(23): 4342-4349.

10. Duffy MJ, Lamerz R, Haglund C, Nicolini A, Kalousová M, Holubec L, et al. Tumor markers in colorectal cancer, gastric cancer and gastrointestinal stromal cancers: European group on tumor markers 2014 guidelines update. Int J Cancer. 2014; 134(11): 2513-2522.

11. Heinrich MC, Corless CL, Duensing A, McGreevey L, Chen C-J, Joseph N, et al. PDGFRA activating mutations in gastrointestinal stromal tumors. Science. 2003; 299(5607): 708-710.

12. Moutinho C, Mateus AR, Milanezi F, Carneiro F, Seruca R, Suriano G. Epidermal growth factor receptor structural alterations in gastric cancer. BMC Cancer. 2008; 8(10): 10.

13. Cohen RB. Epidermal growth factor receptor as a therapeutic target in colorectal cancer. Clin Colorectal Cancer. 2003; 2(4): 246-251.

14. Yarden Y. The EGFR family and its ligands in human cancer. Signalling mechanisms and therapeutic opportunities. Eur J Cancer. 2001; 37(Suppl 4): S3-S8.

15. Voldborg BR, Damstrup L, Spang-Thomsen M, Poulsen HS. Epidermal growth factor receptor (EGFR) and EGFR mutations, function and possible role in clinical trials. Ann Oncol. 1997; 8(12): 1197-1206.

16. Yamaoka T, Ohba M, Ohmori T. Molecular-targeted therapies for epidermal growth factor receptor and its resistance mechanisms. Int J Mol Sci. 2017; 18(11): 2420.

17. Edris B, Espinosa I, Mühlenberg T, Mikels A, Lee $\mathrm{CH}$, Steigen SE, et al. ROR2 is a novel prognostic biomarker and a potential therapeutic target in leiomyosarcoma and gastrointestinal stromal tumour. J Pathol. 2012; 227(2): 223-233.

18. Rubin BP, Heinrich MC, Corless CL. Gastrointestinal stromal tumour. Lancet. 2007; 369(9574): 1731-1741.

19. Hynes NE, Lane HA. ERBB receptors and cancer: The complexity of targeted inhibitors. Nat Rev Cancer. 2005; 5(5): 341-354.

20. Jiang Z, Li C, Li F, Wang X. EGFR gene copy number as a prognostic marker in colorectal cancer patients treated with cetuximab or panitumumab: A systematic review and meta analysis. PLoS One. 2013; 8(2): e56205.

21. Temel S, Uren D, Yakicier MC. Genetics and molecular basis of gastric cancer. In: Canbay E, Zilberstein B, Sossai P, Jinjuvadia K, Catterjee I, Editors. Overview on Gastric Cancer, 3rd ed. Las Vegas, NV, USA: Open Access eBooks. 2018: 1-13.

22. Metro G. EGFR targeted therapy for lung cancer: are we almost there? Transl Lung Cancer Res. 2018; 7(Suppl 2): S142-S145.

23. Ergin K, Gürsoy E, Başimoğlu Koca Y, Başaloğlu H, Seyrek K. Immunohistochemical detection of insulin-like growth factor-I, transforming growth factorbeta2, basic fibroblast growth factor and epidermal growth factor-receptor expression in developing rat ovary. Cytokine. 2008; 43(2): 209-214.

24. Shi S-S, Wu N, He Y, Wei X, Xia Q-Y, Wang X, et al. EFGR gene mutation in gastrointestinal stromal tumors. Histopathology. 2017; 71(4): 553-561.

25. Apicella M, Corso S, Giordano S. Targeted therapies for gastric cancer: Failures and hopes from clinical trials. Oncotarget. 2017; 8(34): 57654-57669.

26. Cancer Genome Atlas Research Network. Comprehensive molecular characterization of gastric adenocarcinoma. Nature. 2014; 513(7517): 202-209.

27. Huss S, Künstlinger H, Warderlmann E, Kleine MA, Binot E, Merkelbach-Bruse S, et al. A subset of gastrointestinal stromal tumors previously regarded as wild-type tumors carries somatic activating mutations in KIT exon 8 (pD419del). Mod Pathol. 2013; 26(7): 1004-1012. 
